\title{
Cancer risk in hospitalised asthma patients
}

\author{
J Ji*, ${ }^{*, 1}$ X Shu', X Li', K Sundquist', J Sundquist ${ }^{2}$ and K Hemminki ${ }^{1,3}$ \\ 'Center for Family and Community Medicine, Karolinska Institute, Huddinge, Sweden; ${ }^{2}$ Center for Primary Health Care Research, Lund University, Lund, \\ Sweden; ${ }^{3}$ Division of Molecular Genetic Epidemiology, German Cancer Research Center (DKFZ), Heidelberg, Germany
}

\begin{abstract}
Asthma is an increasingly common disorder, affecting 5-10\% of the population. It involves a dysregulated immune function, which may predispose to subsequent cancer. We examined cancer risk among Swedish subjects who had hospital admission once or multiple times for asthma. An asthma research database was created by identifying asthma patients from the Swedish Hospital Discharge Register and by linking them with the Cancer Registry. A total of 140425 patients were hospitalised for asthma during 1965-2004, of whom 742I patients developed cancer, giving an overall standardised incidence ratio (SIR) of I.36. A significant increase was noted for most sites, with the exception of breast and ovarian cancers and non-Hodgkin's lymphoma and myeloma. Patients with multiple hospital admissions showed a high risk, particularly for stomach (SIR I.70) and colon (SIR I.99) cancers. A significant decrease was noted for endometrial cancer and skin melanoma. Oesophageal and lung cancers showed high risks throughout the study period, whereas stomach cancer increased towards the end of the period. The relatively stable temporal trends suggest that the asthmatic condition rather than its medication is responsible for the observed associations.

British Journal of Cancer (2009) I 00, 829-833. doi: I0.1038/sj.bjc.6604890 www.bjcancer.com
\end{abstract}

Published online 27 January 2009

(c) 2009 Cancer Research UK

Keywords: asthma; cancer risk; national databases

Asthma is an obstructive lung disease in which recurrent bronchospasms cause breathing difficulties, dyspnoea and wheezing (Holgate and Polosa, 2006). The prevalence of asthma has increased during the past decades and according to a US survey, $8.9 \%$ of the adult population has ever been diagnosed with asthma (Scheller et al, 2006). The annual incidence rate for adults has been 2.2 cases per 1000 persons in the Nordic countries (Toren et al, 2004). An improved hygiene and a drop in exposure to viral and bacterial infections are thought to explain part of the increase (Maddox and Schwartz, 2002; Oh et al, 2004; Yeatts et al, 2006). An enhanced TH2 immune response followed by an increased production of cytokines of type IL- 4 and IL-5 are thought to contribute to the development of asthma (Ngoc et al, 2005). Corticosteroids and $\beta$-adrenergic bronchodilators have been the principal medication for asthma, and from about 1970 these have been administered by inhalation (Chu and Drazen, 2005; Bateman et al, 2008). As newer agents were introduced in the 1990s, antileukotrienes targeted the bronchoconstrictor and anti-IgE block circulating IgE (Chu and Drazen, 2005). The changing asthma treatment in Sweden between 1980 and 1991 led to a 3.8fold increase in the cost of pharmaceuticals, mainly inhaled corticosteroids, which in turn decreased the need for hospital admissions by $35 \%$ in the same period (Jacobson et al, 2000; Bateman et al, 2008).

The immune system has important functions against tumour formation (Swann and Smyth, 2007). Thus, dysregulation of the immune function in conditions such as asthma could potentially lead to cancer development. Some earlier studies have evaluated

*Correspondence: Dr J ji; E-mail: Jianguang.j@ @ki.se

Received 7 November 2008; revised 15 December 2008; accepted 17 December 2008; published online 27 January 2009 the association between a history of asthma and cancer occurrence, but the results have been inconsistent (Alderson, 1974; Vena et al, 1985; Markowe et al, 1987; Reynolds and Kaplan, 1987; Kallen et al, 1993; Vesterinen et al, 1993; Ye et al, 2001; Boffett et al, 2002; Soderberg et al, 2006). Many earlier studies have been small in size and short in follow-up time. To overcome these limitations, we carried out a longitudinal cohort study to quantify the subsequent cancer risk in hospitalised asthma patients, using the Swedish nationwide registers. This study is by far the largest one published on the theme, covering 140425 patients and allowing a separate analysis of patients with multiple hospital admissions and thus with chronic asthma.

\section{PATIENTS AND METHODS}

We used the Swedish Hospital Discharge Register, founded in 1964-65 by the National Board of Health and Welfare with a complete nation-wide coverage since 1987, to create a cohort of asthma patients. Only those patients with hospital admission on account of asthma were included in this study. These patients were retrieved from the registry according to the seventh (1964-68 code 241), eighth (1969-86 code 493), ninth (1987-96 code 493), and tenth (1997 - code J45 and J46) International Classification of Diseases (ICD) codes. However, outpatients were not included in the Swedish Hospital Discharge Register, and therefore these patients were not included in our study. A total of 140425 patients were identified in the registry. The study cohort was linked to the national Swedish Cancer Registry, founded in 1958 with close to $100 \%$ coverage, to ascertain all incident cancers from the start of follow-up until 31 December 2004. The Cancer Registry used a four-digit code according to ICD-7 to identify malignant tumours during the study period. Additional linkages were carried out to 
Table I SIR for subsequent cancer in patients with hospitalised asthma during the follow-up time

\begin{tabular}{|c|c|c|c|c|c|c|c|c|c|c|c|c|c|c|c|c|c|c|}
\hline \multirow[b]{3}{*}{ Cancer site } & \multicolumn{18}{|c|}{ Follow-up interval (years) } \\
\hline & \multicolumn{3}{|c|}{$<\mathbf{I}$} & \multicolumn{3}{|c|}{$1-4$} & \multicolumn{3}{|c|}{$5-9$} & \multicolumn{3}{|c|}{$\geqslant 10$} & \multicolumn{3}{|c|}{ All } & \multicolumn{3}{|c|}{ All I+ } \\
\hline & 0 & SIR & $95 \% \mathrm{Cl}$ & 0 & SIR & $95 \% \mathrm{Cl}$ & o & SIR & $95 \% \mathrm{Cl}$ & o & SIR & $95 \% \mathrm{Cl}$ & $\mathbf{0}$ & SIR & $95 \% \mathrm{Cl}$ & $\mathbf{0}$ & SIR & $95 \% \mathrm{Cl}$ \\
\hline Upper aerodigestive tract & 20 & 1.77 & $(1.08,2.73)$ & 37 & 1.11 & $(0.78,1.53)$ & 36 & 1.26 & $(0.88,1.74)$ & 42 & 1.09 & $(0.79,1.48)$ & 135 & 1.21 & $(1.01,1.43)$ & 115 & 1.14 & $(0.94,1.37)$ \\
\hline Oesophagus & 9 & 1.99 & $(0.90,3.79)$ & 29 & 2.14 & $(1.43,3.08)$ & 28 & 2.39 & $(1.59,3.46)$ & 19 & 1.20 & $(0.72,1.88)$ & 85 & 1.87 & $(1.49,2.31)$ & 76 & 1.85 & $(1.46,2.32)$ \\
\hline Stomach & 49 & 2.41 & $(1.78,3.18)$ & 98 & $\overline{1.72}$ & $(1.40,2.10)$ & 44 & $\overline{0.96}$ & $(0.70,1.30)$ & 68 & 1.20 & $(0.94,1.53)$ & 259 & $\overline{1.44}$ & $(1.27,1.63)$ & 210 & $\overline{1.32}$ & $(1.15,1.51)$ \\
\hline Colon & 98 & $\overline{2.34}$ & $(1.90,2.85)$ & 225 & $\overline{1.77}$ & $(1.55,2.02)$ & 170 & 1.54 & $(1.32,1.79)$ & 210 & 1.42 & $(1.24,1.63)$ & 703 & 1.65 & $(1.53,1.77)$ & 605 & $\overline{1.57}$ & $(1.45,1.70)$ \\
\hline Rectum & 49 & 2.12 & $(1.57,2.81)$ & 82 & $\overline{1.18}$ & $(0.94,1.47)$ & 72 & $\overline{1.20}$ & $(0.94, \mid .51)$ & 108 & $\overline{1.33}$ & $(1.09,1.61)$ & 311 & 1.33 & $(1.19,1.49)$ & 262 & $\overline{1.24}$ & $(1.10,1.40)$ \\
\hline Liver & 48 & $\overline{2.94}$ & $(2.17,3.90)$ & 89 & 1.88 & $(1.51,2.31)$ & 59 & I.5I & $(1.15,1.95)$ & 49 & $\overline{0.99}$ & $(0.73,1.31)$ & 245 & 1.61 & $(1.41,1.82)$ & 197 & $\overline{1.45}$ & $(1.25,1.67)$ \\
\hline Pancreas & 44 & $\overline{2.90}$ & $(2.10,3.89)$ & 58 & $\overline{1.31}$ & $(1.00,1.70)$ & 55 & $\overline{1.50}$ & $(1.13,1.95)$ & 66 & 1.40 & $(1.08,1.78)$ & 223 & $\overline{1.56}$ & $(1.36,1.78)$ & 179 & $\overline{1.40}$ & $(1.20,1.62)$ \\
\hline Lung & 285 & 6.98 & $(6.19,7.84)$ & 294 & 2.41 & $(2.14,2.70)$ & 186 & 1.76 & $(1.52,2.04)$ & 170 & 1.20 & $(1.03,1.40)$ & 935 & 2.28 & $(2.14,2.43)$ & 650 & 1.76 & $(1.63,1.90)$ \\
\hline Breast & 71 & $\overline{1.09}$ & $(0.85,1.38)$ & 221 & $\overline{1.05}$ & $(0.91,1.20)$ & 172 & $\overline{0.89}$ & $(0.76,1.04)$ & 297 & 1.07 & $(0.95,1.20)$ & 761 & $\overline{1.02}$ & $(0.95,1.09)$ & 690 & $\overline{1.01}$ & $(0.94,1.09)$ \\
\hline Cervix & 11 & 1.79 & $(0.89,3.21)$ & 30 & 1.56 & $(1.05,2.23)$ & 20 & 1.18 & $(0.72,1.83)$ & 32 & 1.28 & $(0.87,1.81)$ & 93 & 1.38 & $(1.11,1.69)$ & 82 & 1.34 & $(1.07,1.66)$ \\
\hline Endometrium & 18 & 1.18 & $(0.70,1.87)$ & 36 & 0.74 & $(0.52,1.02)$ & 30 & 0.68 & $(0.46,0.98)$ & 45 & 0.76 & $(0.55,1.01)$ & 129 & 0.77 & $(0.64,0.92)$ & 111 & 0.73 & $(0.60,0.88)$ \\
\hline Ovary & 19 & 1.60 & $(0.96,2.50)$ & 38 & 1.02 & $(0.72,1.40)$ & 29 & 0.89 & $(0.60,1.28)$ & 38 & 0.87 & $(0.61,1.19)$ & 124 & 0.99 & $(0.82,1.18)$ & 105 & 0.92 & $(0.76,1.12)$ \\
\hline Prostate & 178 & 2.12 & $(1.82,2.45)$ & 346 & 1.38 & $(1.24,1.53)$ & 265 & 1.19 & $(1.05,1.35)$ & 397 & 1.26 & $(1.14,1.39)$ & 1186 & 1.36 & $(1.29,1.44)$ & 1008 & 1.28 & $(1.20,1.36)$ \\
\hline Kidney & 38 & $\overline{2.40}$ & $(1.70,3.30)$ & 7I & $\overline{1.55}$ & $(1.21,1.95)$ & 60 & $\overline{1.61}$ & $(1.23,2.07)$ & 38 & $\overline{0.79}$ & $(0.56,1.08)$ & 207 & $\overline{1.41}$ & $(1.22,1.61)$ & 169 & $\overline{1.29}$ & $(1.10,1.50)$ \\
\hline Urinary bladder & 59 & $\overline{2.21}$ & $(1.68,2.85)$ & 117 & $\overline{1.47}$ & $(1.21,1.76)$ & 87 & $\overline{1.26}$ & $(1.01,1.56)$ & 113 & 1.21 & $(1.00,1.45)$ & 376 & $\overline{1.40}$ & $(1.26,1.55)$ & 317 & $\overline{I .3 \mid}$ & $(1.17,1.46)$ \\
\hline Melanoma & 15 & $\overline{1.02}$ & $(0.57,1.69)$ & 30 & $\overline{0.63}$ & $(0.43,0.90)$ & 42 & 0.93 & $(0.67,1.26)$ & 65 & 0.89 & $(0.68,1.13)$ & 152 & $\overline{0.84}$ & $(0.71,0.99)$ & 137 & $\overline{0.83}$ & $(0.69,0.98)$ \\
\hline Skin, squamous cell & 36 & 1.56 & $(1.09,2.16)$ & 92 & 1.28 & $(1.03,1.57)$ & 83 & 1.30 & $(1.04,1.61)$ & 116 & 1.32 & $(1.09,1.59)$ & 327 & 1.33 & $(1.19,1.48)$ & 291 & 1.30 & $(1.16,1.46)$ \\
\hline Nervous system & 48 & 3.01 & $(2.22,3.99)$ & 57 & 1.13 & $(0.86,1.47)$ & 51 & 1.15 & $(0.85,1.51)$ & 66 & $\overline{1.08}$ & $(0.84,1.38)$ & 222 & $\overline{1.29}$ & $(1.13,1.48)$ & 174 & $\overline{1.12}$ & $(0.96,1.30)$ \\
\hline Endocrine glands & 28 & $\overline{3.11}$ & $(2.07,4.51)$ & 33 & 1.18 & $(0.81,1.67)$ & 29 & 1.19 & $(0.79,1.70)$ & 37 & 1.07 & $(0.75,1.47)$ & 127 & $\overline{1.32}$ & $(1.10,1.57$ & 99 & 1.14 & $(0.92,1.39)$ \\
\hline Non-Hodgkin's lymphoma & 42 & 1.87 & $(1.35,2.53)$ & 54 & 0.78 & $(0.58,1.02)$ & 47 & 0.77 & $(0.56,1.02)$ & 87 & 1.03 & $(0.82,1.27)$ & 230 & 0.97 & $(0.85,1.10)$ & 188 & 0.87 & $(0.75,1.01)$ \\
\hline Myeloma & 13 & $\overline{1.65}$ & $(0.87,2.82)$ & 24 & 1.02 & $(0.65,1.52)$ & 21 & 1.05 & $(0.65,1.60)$ & 31 & 1.16 & $(0.79,1.65)$ & 89 & 1.14 & $(0.91,1.40)$ & 76 & 1.08 & $(0.85,1.35)$ \\
\hline Leukaemia & 40 & 3.25 & $(2.32,4.42)$ & 56 & 1.51 & $(1.14,1.96)$ & 47 & 1.56 & $(1.15,2.08)$ & 45 & 1.24 & $(0.90,1.65)$ & 188 & 1.62 & $(1.40,1.87)$ & 148 & 1.43 & $(1.21,1.68)$ \\
\hline All & 1264 & $\overline{2.40}$ & $(2.27,2.54)$ & 2205 & 1.38 & $(1.32,1.44)$ & 1700 & $I .21$ & $(1.15,1.27)$ & 2252 & 1.16 & $(1.11,1.21)$ & 7421 & 1.36 & $(1.33,1.39)$ & 6157 & 1.24 & $(1.21,1.28)$ \\
\hline
\end{tabular}

$\mathrm{Cl}=$ confidence interval; SIR $=$ standardised incidence ratio. Bold values represent $95 \% \mathrm{Cl}$ that does not include I.00. Underlined values represent $99 \% \mathrm{Cl}$ that does not include 1.00 .

Table 2 SIR for subsequent cancer in patients hospitalised for asthma by number of hospitalisations

\begin{tabular}{|c|c|c|c|c|c|c|c|c|c|}
\hline Cancer site & \multicolumn{9}{|c|}{ Number of hospitalisations } \\
\hline Upper aerodigestive tract & 65 & 1.15 & $(0.89,1.47)$ & 43 & 1.31 & $(0.95,1.76)$ & 7 & 0.62 & $(0.24,1.28)$ \\
\hline Oesophagus & 39 & 1.72 & $(1.22,2.36)$ & 30 & 2.21 & $(1.49,3.16)$ & 7 & 1.45 & $(0.57,3.00)$ \\
\hline Stomach* & 98 & $\overline{1.11}$ & $(0.90,1.35)$ & 81 & $\overline{1.54}$ & $(1.22,1.92)$ & 31 & 1.70 & $(1.15,2.41)$ \\
\hline Liver & 110 & $\overline{1.47}$ & $(1.21,1.77)$ & 61 & 1.35 & $(1.03,1.73)$ & 26 & 1.62 & $(1.06,2.38)$ \\
\hline Pancreas & 97 & 1.37 & $(1.11,1.67)$ & 59 & 1.39 & $(1.06,1.80)$ & 23 & 1.55 & $(0.98,2.33)$ \\
\hline Lung*** & 402 & 1.96 & $(1.78,2.16)$ & 190 & 1.56 & $(1.35,1.80)$ & 58 & 1.36 & $(1.04,1.76)$ \\
\hline Breast & 399 & $\overline{1.04}$ & $(0.94,1.14)$ & 217 & $\overline{0.98}$ & $(0.85,1.12)$ & 74 & 0.99 & $(0.78,1.24)$ \\
\hline Cervix & 46 & 1.30 & $(0.95,1.73)$ & 28 & 1.43 & $(0.95,2.07)$ & 8 & 1.29 & $(0.55,2.55)$ \\
\hline Endometrium & 67 & 0.79 & $(0.62,1.01)$ & 36 & $0.7 I$ & $(0.50,0.99)$ & 8 & 0.46 & $(0.19,0.90)$ \\
\hline Ovary & 60 & 0.93 & $(0.71,1.20)$ & 34 & 0.92 & $(0.63,1.28)$ & II & 0.90 & $(0.44,1.61)$ \\
\hline Nervous system & 93 & $\overline{1.01}$ & $(0.81,1.23)$ & 58 & 1.19 & $(0.91,1.54)$ & 23 & $\overline{1.58}$ & $(1.00,2.38)$ \\
\hline Endocrine glands & 70 & 1.42 & $(1.11,1.79)$ & 23 & 0.81 & $(0.51,1.22)$ & 6 & 0.64 & $(0.23,1.40)$ \\
\hline Non-Hodgkin's lymphoma & 90 & $\overline{0.75}$ & $(0.60,0.92)$ & 71 & 0.01 & $(0.79,1.27)$ & 27 & 1.11 & $(0.73,1.62)$ \\
\hline Myeloma & 42 & 1.08 & $(0.78,1.47)$ & 24 & 1.03 & $(0.66,1.54)$ & 10 & 1.21 & $(0.58,2.24)$ \\
\hline Leukaemia & 89 & 1.46 & $(1.17,1.80)$ & 47 & 1.45 & $(1.07,1.93)$ & 12 & 1.18 & $(0.61,2.07)$ \\
\hline All & 3407 & $\overline{1.23}$ & $(1.19,1.27)$ & 2028 & 1.25 & $(1.20,1.30)$ & 722 & 1.29 & $(1.20,1.38)$ \\
\hline
\end{tabular}

$\mathrm{Cl}=$ confidence interval; $\mathrm{SIR}=$ standardised incidence ratio. Bold values values represent $99 \% \mathrm{Cl}$ that does not include $1.00 . * P$-value for trend is $<0.05 . * * P$-value for trend is $<0.01$.

the national census data to obtain individual occupational status, to the National Registry of Causes of Death to identify the date of death, and to the Emigration Registry to identify the date of emigration. All linkages were carried out by the use of an individual national identification number that is assigned to each person in Sweden for his or her lifetime. This number was replaced by a serial number for each person in order to provide anonymity.

Person-years were calculated from the last hospital admission for asthma until diagnosis of cancer, death, emigration or closing date (31 December 2004), whichever came first. The follow-up time 
Table 3 SIR for subsequent cancer in patients with hospitalised asthma during diagnosis period

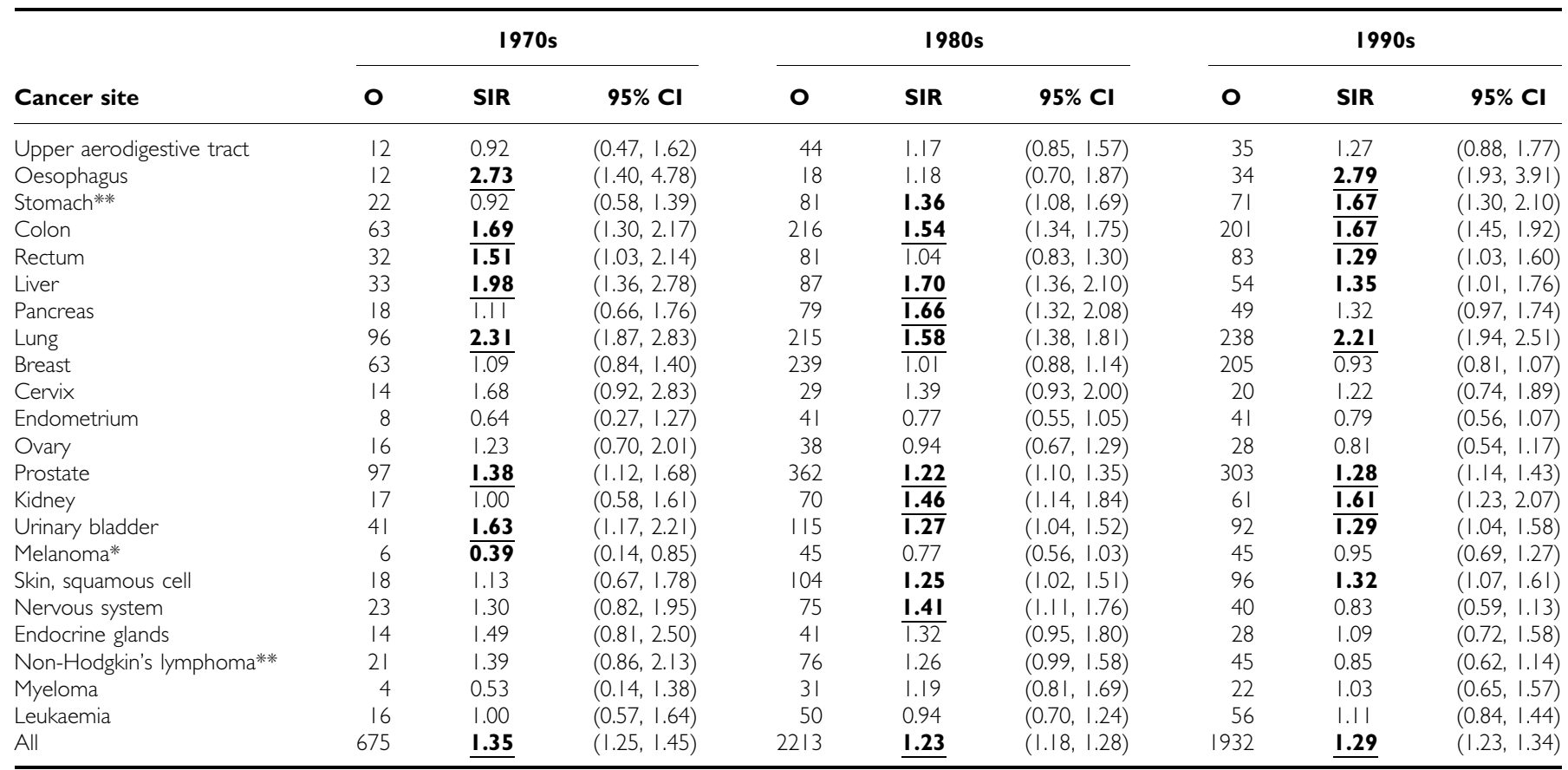

$\mathrm{Cl}=$ confidence interval; $\mathrm{SIR}=$ standardised incidence ratio. Bold values represent $95 \% \mathrm{Cl}$ that does not include 1.00 . Underline values represent $99 \% \mathrm{Cl}$ that does not include 1.00. * $P$-value for trend is $<0.05$. ** $P$-value for trend is $<0.01$

was divided into four periods: $<1,1-4,5-9$ and $\geqslant 10$ years. Standardised incidence ratios (SIRs) were calculated as the ratio of observed to expected number of cases. The expected numbers were calculated by the incidence rates for all individuals without a history of asthma, and the incidence rates in the reference group were similar to the general population in our database. The rates were standardized by 5 -year age, gender, period (5-year group), socioeconomic status, and residential area (Esteve et al, 1994). For cancers of the female reproductive system, age at first childbirth and parity were also standardised. The $95 \%$ confidence interval of the SIR was calculated assuming a Poisson distribution, and they were rounded to the nearest two decimals (Esteve et al, 1994). Temporal trend was tested based on the $\chi^{2}$ distribution of the test statistic $\chi^{2}$ with 1 degree of freedom. All analyses were performed using the SAS statistical package (version 9.1; SAS Institute, Cary, NC, USA). The ethics committee at Karolinska Institute, Stockholm, Sweden, approved this study.

\section{RESULTS}

A total of 140425 patients were hospitalised in Sweden for asthma during 1965-2004; among them 83098 (59.2\%) patients were hospitalised only once, 22338 (15.9\%) twice, 10253 (7.3\%) thrice, $5836(4.2 \%)$ for four times, $3717(2.7 \%)$ for five times, and 15183 $(8.7 \%)$ for more than five times. A total of 7421 patients developed subsequent cancer after being hospitalised for asthma, giving an overall SIR of 1.36 and a SIR of 1.24 for cancer diagnosed later than 1 year of the last hospital admission (all $1+$ ), as shown in Table 1 . Only those cancer sites with at least 60 cases during the whole follow-up period were listed. The risk for some cancer sites, such as lung cancer and leukaemia, was high during the first year, probably because of a concomitant diagnosis of asthma and cancer. Thus, we show the data for the whole follow-up period and $1+$, respectively; the results agreed for significant increases and decreases for almost all the examined cancers. The highest overall increase of 2.28 was noted for lung cancer, and the increases were noted in the whole follow-up periods. Even all the other cancers, with an exception for breast and ovarian cancers and non-Hodgkin's lymphoma and myeloma, showed a significantly increased SIR. A significantly decreased SIR was noted for endometrial cancer (0.77) and skin melanoma (0.84).

Multiple hospital admissions may reflect the disease severity, and we examined cancer risk by the number of hospital admissions by starting the follow-up after the last admission (Table 2). The overall SIR was 1.23 for asthma patients who have been hospitalised once, and it was slightly increased to 1.25 for those with 2-5 hospital admissions and to 1.29 for those with more than five hospital admissions. The SIR was higher for almost all cancers when asthma patients had multiple hospital admissions, with an exception for lung, bladder and endocrine gland tumours, and leukaemia. We tested for the significance of the trend in the number of hospital admissions (see asterisk after 'cancer site'). Stomach and colon cancers and non-Hodgkin's lymphoma showed an increasing trend with the number of admissions, whereas a reverse trend was noted for lung cancer. In those hospitalised more than five times, the SIR of kidney cancer exceeded that of lung cancer.

To study the periodic effects in respect to the changing therapeutic regimens and diagnosis criteria, we analysed cancer risk among asthma patients who were hospitalised in the 1970s, 1980 s, and 1990s (Table 3). As maximally 14 years could be followed up for those who had been hospitalised in the 1990s, analyses were limited to cancers diagnosed 1-14 years after the last hospital admission. The overall SIR was marginally higher for the patients hospitalised in the 1970s compared with those hospitalised later. The highest risk (2.79) was noted for oesophageal cancer when patients were hospitalised in the 1990s. We tested for the significance of the temporal trends. The risk for stomach cancer and melanoma showed an increasing temporal trend, whereas a reverse trend was noted for non-Hodgkin's lymphoma. 


\section{DISCUSSION}

In this population-based study, 140425 asthma patients were identified from the Swedish Hospital Discharge Register and were followed up to 40 years, an observation time longer than that in any published study on this theme. The additional strengths of our study include its population-based prospective design and completeness of follow-up of the patients. All the data were from nation-wide databases guaranteeing reliable information. One limitation of this study is that because multiple comparisons were performed, some of the findings may be due to chance. The lack of information regarding medication and treatment and regarding the possible confounding factors, such as smoking, is another limitation. Moreover, the data from this study are not directly applicable to all patients with asthma because outpatients were not included in this study and hospitalised patients probably represent a severe and chronic clientele.

Overall, a $36 \%$ excess incidence of cancer was noted among asthma patients who had been treated in hospitals. Most earlier studies reported a reverse association or no association between asthma and the overall cancer risk (Kallen et al, 1993; Turner et al, 2005, 2006); a Swedish study from the earlier days of the Hospital Discharge Register reported a decreased mortality of $66 \%$ (Kallen et al, 1993). According to a recent review on cancer risk in asthma (Turner et al, 2006), only one Finnish cohort study has shown a positive association (Vesterinen et al, 1993), but significant only for men. The number of cancer cases in our study was almost the sum of cases in three earlier cohort studies (Kallen et al, 1993; Vesterinen et al, 1993; Turner et al, 2005). For the cancers overall, the highest risks were noted during the first year after last hospital admission for asthma, which could be due to lead time bias because of concomitant diagnosis. However, these earlier cancers were so few that the SIRs calculated for the whole follow-up period and for the whole period minus the first year were basically unchanged.

For specific cancers, some of the observed associations have been reported earlier. The increased risk for lung cancer was noted in many earlier studies (Vesterinen et al, 1993; Huovinen et al, 1997; Mayne et al, 1999; Boffett et al, 2002). Smoking is a common risk factor for lung cancer and asthma (Silverman et al, 2003; Eisner, 2008). The excess of bladder and kidney cancers in our study may also reflect confounding by smoking; however, the data on the number of hospital admissions and on temporal trends for kidney and lung cancers suggest that non-smoking-related factors contribute to kidney cancer, particularly towards the end of the study period. An increase in oesophageal and stomach cancers was reported earlier and partly attributed to gastro-oesophageal reflux caused by $\beta$-adrenergic medication (Ye et al, 2001). A significant increase of rectal cancer has been reported among Finnish women (Vesterinen et al, 1993), whereas an excess of prostate cancer has been reported in cohort studies from Japan and Australia (Ohrui et al, 2002; Talbot-Smith et al, 2003).

The increased risks in cancers of the colon, liver, and pancreas have not been reported earlier and most earlier studies have shown a reduced risk or risk close to unity (Vesterinen et al, 1993; Talbot-Smith et al, 2003; Turner et al, 2005). The excess of colon cancer increased with the number of hospital admissions and the SIR was 1.99 for those hospitalised more than 5 times, highest for

\section{REFERENCES}

Ahmed SA, Hissong BD, Verthelyi D, Donner K, Becker K, KarpuzogluSahin E (1999) Gender and risk of autoimmune diseases: possible role of estrogenic compounds. Environ Health Perspect 107(Suppl 5): 681-686

Alderson M (1974) Mortality from malignant disease in patients with asthma. Lancet 2: $1475-1477$

Bateman ED, Hurd SS, Barnes PJ, Bousquet J, Drazen JM, FitzGerald M, Gibson P, Ohta K, O'Byrne P, Pedersen SE, Pizzichini E, Sullivan SD, any cancer, suggesting a true aetiological link. IL-6 trans-signalling is critically involved in the maintenance of both asthma and colon cancer (Scheller et al, 2006). Asthma medications may also play a role in this association (Friedman et al, 1998). Although a recent review reported no association with pancreatic cancer (Turner et al, 2006), a 56\% excess was noted in our study and the risk was significant even after 1 year of hospital admission. An increased occurrence of squamous cell skin cancer has not been reported earlier. This cancer is one of the hallmarks of dysregulated immunity; another hallmark, non-Hodgkin's lymphoma, showed no increase and a decrease in those hospitalised only once. The decrease in endometrial cancer raised the possibility that dysregulated immune function among asthma patients may affect oestrogen production (Ahmed et al, 1999; Hemminki et al, 2008). The only other tumour with a decreased risk was melanoma, but only in asthmatics diagnosed in the 1970s. The increase in cervical cancer may signal vulnerability to infection by human papillomaviruses; immune impairment is a risk factor for cervical cancer. In contrast to the inverse association between asthma and leukaemia in the earlier studies, an increased risk was noted in our study. The positive associations with cancers of the upper aerodigestive tract, nervous system, and endocrine glands were confined for the first year after hospital admission, suggesting that they were due to the lead-time bias.

We examined the study group by the number of hospital admissions, using this as a surrogate for disease severity and chronicity. The overall cancer risk was not affected, but there were large differences by cancer types. The excess in stomach, colon, liver and skin cancers were most pronounced with multiple hospital admissions, and so was the protection in endometrial cancer. For oesophageal cancer, the highest risk of 2.21 was noted for those hospitalised 2-5 times. The two-fold risk of colon cancer may indicate medical surveillance.

The diagnostic criteria and treatment for asthma patients have changed during the follow-up period. We examined the temporal trends of cancer development among asthma patients. The overall risk was marginally higher for patients hospitalised in the 1970s compared with the later periods, and for the most specific cancers the risk did not change or decreased slightly during the study period. In view of the large increase in medications, the relatively constant risks observed throughout the study period suggest that the medical condition 'asthma' rather than its medication may be associated with cancer risk. However, the increasing temporal trend for stomach cancer calls for clinical attention.

In summary, a $36 \%$ excess incidence of cancer was noted among asthma patients. The robust relative risks and their consistency with multiple hospital admissions suggest real associations with several cancer sites and protection for endometrial cancer, more likely with the disorder than with its medication.

\section{ACKNOWLEDGEMENTS}

This study was supported by Deutsche Krebshilfe, the Swedish Cancer Society, the EU, LSHC-CT-2004-503465, and the Swedish Council for Working Life and Social Research.
Wenzel SE, Zar HJ (2008) Global strategy for asthma management and prevention: GINA executive summary. Eur Respir J 31: 143-178

Boffett P, Ye W, Boman G, Nyren O (2002) Lung cancer risk in a population-based cohort of patients hospitalized for asthma in Sweden. Eur Respir J 19: $127-133$

Chu EK, Drazen JM (2005) Asthma: one hundred years of treatment and onward. Am J Respir Crit Care Med 171: $1202-1208$ 
Eisner MD (2008) Passive smoking and adult asthma. Immunol Allergy Clin North Am 28: 521 -537, viii

Esteve J, Benhamou E, Raymond L (1994) Statistical Methods in Cancer Research. IARC: Lyon

Friedman GD, Coates AO, Potter JD, Slattery ML (1998) Drugs and colon cancer. Pharmacoepidemiol Drug Saf 7: 99-106

Hemminki K, Li X, Sundquist K, Sundquist J (2008) Cancer risk in hospitalized rheumatoid arthritis patients. Rheumatology (Oxford) 47: $698-701$

Holgate ST, Polosa R (2006) The mechanisms, diagnosis, and management of severe asthma in adults. Lancet 368: 780-793

Huovinen E, Kaprio J, Vesterinen E, Koskenvuo M (1997) Mortality of adults with asthma: a prospective cohort study. Thorax 52: 49-54

Jacobson L, Hertzman P, Lofdahl CG, Skoogh BE, Lindgren B (2000) The economic impact of asthma and chronic obstructive pulmonary disease (COPD) in Sweden in 1980 and 1991. Respir Med 94: 247-255

Kallen B, Gunnarskog J, Conradson TB (1993) Cancer risk in asthmatic subjects selected from hospital discharge registry. Eur Respir J 6: 694-697

Maddox L, Schwartz DA (2002) The pathophysiology of asthma. Annu Rev Med 53: $477-498$

Markowe HL, Bulpitt CJ, Shipley MJ, Rose G, Crombie DL, Fleming DM (1987) Prognosis in adult asthma: a national study. Br Med J (Clin Res Ed) 295: $949-952$

Mayne ST, Buenconsejo J, Janerich DT (1999) Previous lung disease and risk of lung cancer among men and women nonsmokers. Am J Epidemiol 149: $13-20$

Ngoc PL, Gold DR, Tzianabos AO, Weiss ST, Celedon JC (2005) Cytokines, allergy, and asthma. Curr Opin Allergy Clin Immunol 5: 161-166

Oh JC, Wu W, Tortolero-Luna G, Broaddus R, Gershenson DM, Burke TW, Schmandt R, Lu KH (2004) Increased plasma levels of insulin-like growth factor 2 and insulin-like growth factor binding protein 3 are associated with endometrial cancer risk. Cancer Epidemiol Biomarkers Prev 13: $748-752$

Ohrui T, Yamaya M, Sato T, Matsui T, Sasaki H, Namima T (2002) Risk of prostate cancer in older Japanese asthmatics. J Am Geriatr Soc 50: 202
Reynolds P, Kaplan GA (1987) Asthma and cancer. Am J Epidemiol 125: $539-540$

Scheller J, Ohnesorge N, Rose-John S (2006) Interleukin-6 trans-signalling in chronic inflammation and cancer. Scand J Immunol 63: $321-329$

Silverman RA, Boudreaux ED, Woodruff PG, Clark S, Camargo Jr CA (2003) Cigarette smoking among asthmatic adults presenting to 64 emergency departments. Chest 123: $1472-1479$

Soderberg KC, Jonsson F, Winqvist O, Hagmar L, Feychting M (2006) Autoimmune diseases, asthma and risk of haematological malignancies: a nationwide case-control study in Sweden. Eur J Cancer 42: 3028-3033

Swann JB, Smyth MJ (2007) Immune surveillance of tumors. J Clin Invest 117: $1137-1146$

Talbot-Smith A, Fritschi L, Divitini ML, Mallon DF, Knuiman MW (2003) Allergy, atopy, and cancer: a prospective study of the 1981 Busselton cohort. Am J Epidemiol 157: 606-612

Toren K, Gislason T, Omenaas E, Jogi R, Forsberg B, Nystrom L, Olin AC, Svanes C, Janson C (2004) A prospective study of asthma incidence and its predictors: the RHINE study. Eur Respir J 24: $942-946$

Turner MC, Chen Y, Krewski D, Ghadirian P (2006) An overview of the association between allergy and cancer. Int J Cancer 118: 3124-3132

Turner MC, Chen Y, Krewski D, Ghadirian P, Thun MJ, Calle EE (2005) Cancer mortality among US men and women with asthma and hay fever. Am J Epidemiol 162: 212-221

Vena JE, Bona JR, Byers TE, Middleton Jr E, Swanson MK, Graham S (1985) Allergy-related diseases and cancer: an inverse association. Am J Epidemiol 122: 66 - 74

Vesterinen E, Pukkala E, Timonen T, Aromaa A (1993) Cancer incidence among 78000 asthmatic patients. Int J Epidemiol 22: 976-982

Ye W, Chow WH, Lagergren J, Boffetta P, Boman G, Adami HO, Nyren O (2001) Risk of adenocarcinomas of the oesophagus and gastric cardia in patients hospitalized for asthma. Br J Cancer 85: 1317-1321

Yeatts K, Sly P, Shore S, Weiss S, Martinez F, Geller A, Bromberg P, Enright P, Koren H, Weissman D, Selgrade M (2006) A brief targeted review of susceptibility factors, environmental exposures, asthma incidence, and recommendations for future asthma incidence research. Environ Health Perspect 114: 634-640 